\title{
A discrete macro-model homogenized with a holonomic approach for the nonlinear static analysis of out-of-plane loaded masonry
}

\author{
Luís Carlos Silva \\ ISISE, Universidade do Minho, Guimarães, Portugal \\ Gabriele Milani \\ Technical University of Milan, Milan, Italy \\ Paulo B. Lourenço \\ ISISE, Universidade do Minho, Guimarães, Portugal
}

\begin{abstract}
A simple homogenized model based on a holonomic approach is presented, aiming at the study of the non-linear behaviour of masonry walls subjected to two-way bending. Firstly, a representative volume element (RVE) of a running bond elementary cell is defined at a meso-scale. The RVE is subdivided into several layers along the thickness. For each layer a plane stress assumption is considered, whereas bricks are discretized as threenode triangular elements and the joints reduced to interfaces. The non-linearity is present only at the interfaces, which exhibit a holonomic behaviour with softening. At structural scale, the obtained homogenized curves serve as input for the interfaces of a new discrete system implemented in a finite element commercial package, to perform non-linear static (pushover) analysis of masonry walls under two-way bending. The developed discrete macro-model is based on quadrilateral rigid element discretization, where flexural deformation is allowed only at the interfaces through a system of axial and torque trusses. The behaviour of the interfaces is obviously holonomic and orthotropic with softening, because they are derived from the aforementioned homogenization strategy. Several examples of technical relevance relying into windowed panels out-of-plane loaded up to failure are analysed in detail, finding a satisfactory match between present results and previously presented approaches available in the technical literature.
\end{abstract}

\section{INTRODUCTION}

Masonry is an assemblage of units and joints (mortar, glue etc.). Thus, it is a heterogeneous composite material with distinct directional properties, being the joints planes of weakness (Lourenço 2008). In addition, the geometrical variability of its components (size of units) and the possibilities for the arrangement between them increases the complexity of masonry structures' analysis.

Moreover, the intervention process on historic unreinforced masonry structures is complex (Lourenço 2002) not only due to lack of structural information but also due to its intangible importance. It is known that existing masonry buildings present, in general, high seismic vulnerability, which is related with its (i) low resistance to horizontal forces, (ii) lack of capacity to dissipate energy and (iii) absence of seismic requirements in the time of its construction (Bruneau 1994).

Recent earthquakes highlighted the vulnerability of existing old masonry buildings. The out-of-plane collapse mechanisms are the most prone to occur (Spence \& Coburn 1992), due to the poor out-of-plane strength of masonry. Several post-earthquakes damage surveys conducted in Italy (D'Ayala \& Paganoni 2010) (Kaplan et al. 2010) (Sorrentino et al. 2013) and New Zealand (Dizhur et al. n.d.) (Silva 2013) address the latter.

The numerical analysis of historical constructions in the inelastic range through FE include different modelling approaches. These modelling strategies try to represent masonry at different material scales: (i) the micro-modelling) (Lourenço 1996); (ii) the macromodelling approach (Lourenço et al. 1997) (Lourenço 2000) (Roca et al. 2013) (Peña et al. 2010) (Mendes \& Lourenço 2014), and (iii) the homogenization process (Luciano \& Sacco 1997; Milani \& Lourenço 2010; Casolo \& Milani 2013).

On one hand, continuum FE macro-models are very used to analyse and identify local failures on historical structures (Roca et al. 2013; Lourenço et al. 2007). On the other hand, as the heterogeneity of the masonry influences the failure behaviour and capacity (de Felice 2011), discrete (micro-) models are likely to provide more accurate solutions, even if the accurate knowledge of the masonry arrangement is usually unknown in historic construction. Still, it is known 
that a heterogeneous discretization of masonry, i.e. a distinct representation of joints and blocks, can lead to accurate results. As a drawback, difficulties at the modelling stage are higher and more critical computational times are required.

Thus, a homogenization-based approach which accounts for the masonry heterogeneity in a regular assemblage pattern is a powerful tool. This strategy is being successfully applied in the field of limit analysis for the study of the out-of-plane behaviour of masonry, see (Milani \& Tralli 2011; Milani et al. 2006; Milani et al. 2007; Milani \& Lourenço 2010; Casolo \& Milani 2013).

The present paper introduces a new strategy for the study of masonry panels out-of-plane loaded. At a meso-scale, the developed procedure relies on a homogenized model based on a holonomic approach. It allows to obtain different moment-curvature curves with softening, according to the flexural axis in order to reproduce masonry orthotropy. This information is consequently assigned to the macro-scale model. The latter is based on a discrete system composed by quadrilateral rigid plates connected by a system of rigid beams, axial and torque trusses. The novel discrete macro-model will be implemented in a Finite Element package, ABAQUS (Abaqus 2008). It allows to run the non-linear static analysis and to use robust standardized and commercially maintained tools to solve non-linear problems involving the material softening.

The paper is organized as follows: in section 2 , the homogenized model is briefly explained. In section 3, the macro-model is presented, as well as, its material properties assignment and implementation in the finite element package ABAQUS. In section 4, the comparison between numerical and experimental data available in the literature for masonry panels under two-way bending is performed and the results are discussed. At last, section 5 concerns the conclusion and final remarks.

\section{MESO-SCALE - HOMOGENIZATION}

\subsection{Introduction}

There are several strategies to idealize masonry. As already stated, these approaches designated by microand macro-modelling vary in the structural scale level of analysis. The former allows to obtain results with great accuracy, however, its complexity at the modelling stage and the considerable time required to compute the results makes it more suitable for the analysis of masonry walls with small dimensions. The later, in which masonry is considered as a fictitious homogeneous and isotropic material, is very useful to the study of large structures, however, lacks accuracy at a local scale.

In this way, the homogenization approach tries to fill the gap between micro- and macro-models. This strategy is being extensively studied in the field of composite materials (Geers et al. 2010). The homogenization theory focused on the periodicity feature of a given media is a proper strategy for masonry (Pegon \& Anthoine 1997). The concept stands on the mechanical characterization of a representative volume element by solving a boundary value problem; then, the study of the structure is accomplished through the assemblage of these RVE units. The strategy allows to define the mechanical properties of each material at the unit cell, and obtaining the stress and strain response by introducing considerations at these state fields.

Several studies showed the clear advantages of this process. It allows a good trade-off between consumed time and results' accuracy, and enables the study of real scale buildings (Milani \& Tralli 2011; Milani \& Venturini 2011; Casolo \& Milani 2013; Akhaveissy \& Milani 2013; Milani et al. 2007).

\subsection{Homogenization model}

The homogenization model is based on the identification of an elementary cell or Representative Element of Volume (hereafter, RVE). The RVE is constituted by elastic blocks and joints reduced to interface with a homogeneous plate. For further information, see [13] (Milani \& Tralli 2011).

The representative element of volume $Y$ (RVE or elementary cell) contains all the information necessary for describing completely the macroscopic behaviour of an entire wall.

Homogenization consists in introducing averaged quantities for macroscopic strain and stress tensors (E and $\Sigma$, respectively). This is the main concept of the homogenisation process and implies that the macroscopic stress $\Sigma$ and strain $E$ tensors are calculates as:

$$
\mathrm{E}=\left\langle\varepsilon>\int_{Y} \frac{\varepsilon(u) d Y}{V} ; \Sigma=\langle\sigma\rangle \int_{Y} \frac{\sigma}{V} d Y\right.
$$

where $<^{*}>$ is the average operator, $\varepsilon$ is the local strain value, which is directly dependent of the displacements field $u, \sigma$ is the local stress value and $V$ is the volume of each elementary cell. The homogenization procedure pretends to describe the macroscopic level based on the micro- or meso-scale; the so-called up-ward procedure. All the mechanical quantities are considered as addictive functions and periodicity conditions are imposed on the stress field $\sigma$ and the displacement field $u$ (Anthoine 1995), so that:

\section{$\sigma \quad$ periodic on $\partial Y$ and $\sigma n$ antiperiodic on $\partial Y_{1}$}

$u^{\text {per }}$ periodic on $\partial Y_{1}$

In the present model, joints are reduced to interfaces with zero thickness and bricks are discretized by means of a coarse mesh constituted by plane-stress elastic triangles, Figure 1. All the non-linearity in the RVE is concentrated exclusively on interfaces between adjoining elements, both on brick and joint.

The elastic domain of joints is bound by a composite yield surface that includes tension, shear and compression failure with softening (see Fig. 2). A multi-surface 


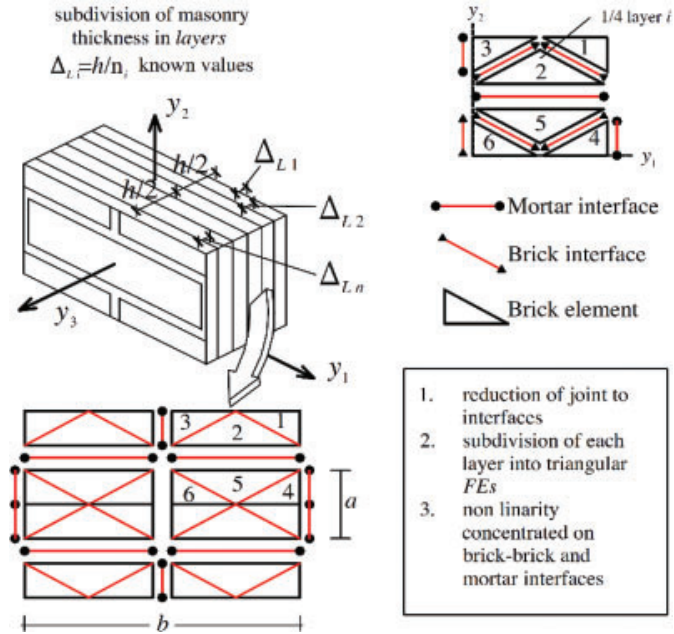

Figure 1. Micro-mechanical model (Milani \& Tralli 2011).

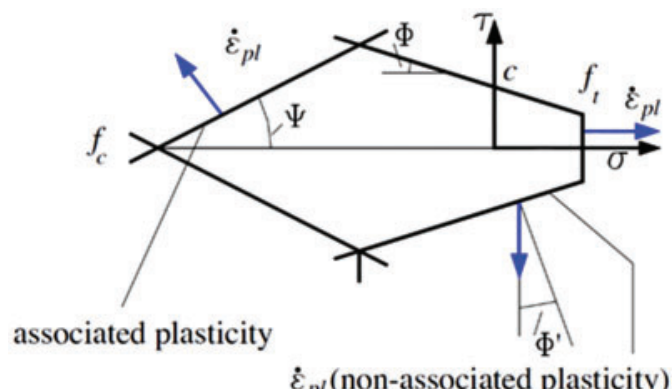

Figure 2. Modified Mohr-Coulomb criterion for the mortar joint/mortar-brick interface (Milani \& Tralli 2011).

plasticity model is adopted, with softening, both in tension and compression. The parameters $f_{t}$ and $f_{c}$ are, respectively, the tensile and compressive ModeI strength of the mortar or mortar-brick interfaces, c is the cohesion, $\Phi$ is the friction angle, and $\Psi$ is the angle which defines the linear compression cap.

The response of the RVE under out-of-plane actions is obtained subdividing along the thickness the unit cell into several layers. A displacement driven approach is adopted, meaning that macroscopic curvature increments $\Delta \chi_{11}, \Delta \chi_{22}, \Delta \chi_{33}$ are applied through suitable periodic boundary displacement increments. Thus, each layer undergoes only in-plane displacements and may be modelled through plane stress FEs. Bending moments and torsion are finally obtained at each step simply by integration along the thickness of the quantity $\sigma \mathrm{y}_{3}$.

$\mathrm{M}=<\sigma y_{3}>=\frac{1}{A} \int_{Y} \sigma y_{3} d Y$

The nonlinear curvature-bending moment flexural behaviour of the interfaces is approximated using holonomic curves, see Figure 3. The implementation of the latter in a finite element package at a macro-scale
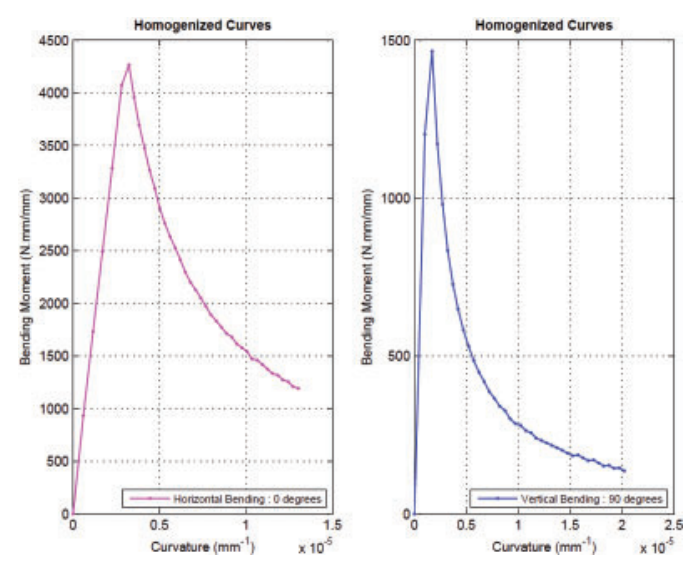

Figure 3. Holonomic bending moment-curvature homogenized curves.

will allow to represent and study three-dimensional structures due to out-of-plane actions.

\section{MACRO-SCALE MODEL}

\subsection{The discrete element model}

On a macro-scale level the out-of-plane analysis of the masonry walls will be performed through a novel discrete element system. The latter has support and background in the works of Kawai (Kawai 1977). Simply, it is described as the assemblage of quadrilateral rigid plates inter-connected on its interface vertices' by a set of rigid and truss beams. Plus, in the mid-span of each interface a spherical hinge is positioned. The aim is to guarantee the deformed shape compatibility between adjoining elements. For a clear understanding of the model, the discrete system is represented in Figure 4.

The discrete element approach was modelled in a commercial finite element software, ABAQUS (Abaqus 2008). The inherent advantages are mainly two. Firstly, the robustness of the software to solve the equilibrium system of equations; the performed non-linear static analysis combined with the representation of masonry softening demand an arc-length procedure (Memon \& Su 2004). Secondly, the potential to extend it to several structural applications in any finite element software and the possibility to be used by professionals and researchers.

However, the material properties should be addressed for each truss. In order to accomplish a proper calibration of the input curves, a proper identification of the desired mesh dimensions and geometrical characteristics of the wall are required.

\subsection{Material properties: From meso- to macro-scale}

The masonry behaviour when out-of-plane loaded is highly dependent of its anisotropy at failure (Gilbert 

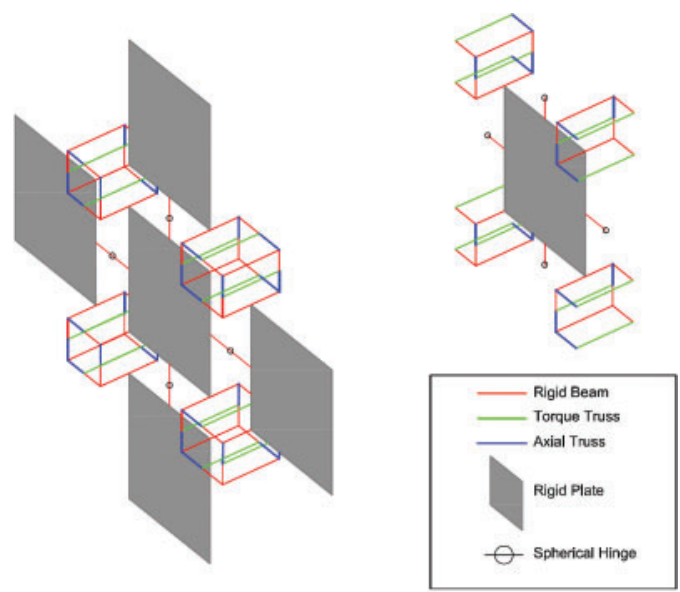

Figure 4. Description of the novel discrete element system.

et al. 2006; Milani \& Lourenço 2010). Experimental information conducted on entire masonry walls in twoway bending prove that failure occurs for a relatively ductile behaviour and along a well-defined path, see (Southcombe et al. 1995; Chong et al. 1994).

Moreover, the previously presented homogenized masonry model, implemented at a structural level in a finite element code, allow to obtain the holonomic stress-strain curves of the RVE. It offers the possibility to reproduce the masonry orthotropy. Bearing that quadrilateral elements are assumed, in a macro- scale, two different angles were considered for the interfaces: $0^{\circ}$ and $90^{\circ}$.

The holonomic stress-strain relationships curves from homogenization will allow to obtain the bending moments and torsion curves, simply by integration along the thickness of the wall (40 layers were considered for the effect). However, a calibration is required. This process has into account the mesh discretization, i.e. geometrical data of the quadrilateral panels.

Equations (5) and (6) define the conversion between bending moment for stress values. After this step, the curves are calibrated in accordance to the elastic Young modulus. The elastic parameters identification was performed for both axial and torque trusses through an energetic approach between the discrete model cell and a continuous plate.

$$
\begin{aligned}
& \sigma_{\text {axial truss }}=\frac{M \times L_{\text {influence }}}{\left(A_{\text {Axial }} \times t\right)} \\
& \sigma_{\text {torque truss }}=\frac{M \times L_{\text {influence }}}{\left(A_{\text {Torque }} \times H\right)}
\end{aligned}
$$

Here, $M$ is the bending moment, $L_{\text {influence }}$ is the influence length of each truss, $t$ is the thickness of the wall, $H$ the length of each quadrilateral panel, $A_{\text {Axial }}$ is the axial truss area given by $0.25 \times \mathrm{t} \times \mathrm{H}$ and $A_{\text {Torque }}$ is the torque truss area given by $0.5 \times \mathrm{e} \times \mathrm{H}$, where $e$ is the gap between the rigid plates, which ideally should be zero.

It is important to stress that the present study focuses on the nonlinear static analysis of masonry panels; and
Table 1. Mechanical properties for the homogenization step, see (Chong et al. 1994).

\begin{tabular}{lll}
\hline Parameter & Joint & $\begin{array}{l}\text { Brick-brick } \\
\text { interface }\end{array}$ \\
\hline Young's Modulus $(\mathrm{E})$ & $3500 \mathrm{MPa}$ & $10,000 \mathrm{MPa}$ \\
Shear Modulus $(\mathrm{G})$ & $1500 \mathrm{MPa}$ & $5000 \mathrm{MPa}$ \\
Cohesion $(\mathrm{c})$ & $1.2 \times \mathrm{f}_{\mathrm{t}} \mathrm{MPa}$ & $1 \mathrm{MPa}$ \\
Tensile strength $\left(\mathrm{f}_{\mathrm{t}}\right)$ & $0.58 \mathrm{MPa}$ & - \\
Compressive strength $\left(\mathrm{f}_{\mathrm{c}}\right)$ & $2.00 \mathrm{MPa}$ & - \\
Friction angle $(\phi)$ & $30^{\circ}$ & $45^{\circ}$ \\
$\begin{array}{l}\text { Linearized compressive } \\
\text { cap angle }(\psi)\end{array}$ & $50^{\circ}$ & - \\
$\begin{array}{l}\text { Mode I fracture energy }\left(G_{f}^{I}\right) \\
\text { Mode II fracture energy }\left(G_{f}^{I I}\right)\end{array}$ & $0.010 \mathrm{~N} / \mathrm{mm}$ & $10 \mathrm{~N} / \mathrm{mm}$ \\
& $0.012 \mathrm{~N} / \mathrm{mm}$ & $10 \mathrm{~N} / \mathrm{mm}$ \\
\hline
\end{tabular}

that the walls under study were already experimentally out-of-plane tested, see (Chong et al. 1994). Also, it is highlighted that for the present study a refined mesh was defined. The size of the interfaces $(H)$, i.e. the side length of each quadrilateral panel, is $100 \mathrm{~mm}$.

Insomuch, at a meso-scale, the mechanical properties adopted for the RVE characterization are presented in Table 1. Bearing that according with the experimental data (Chong et al. 1994; Southcombe et al. 1995), the flexural uniaxial strengths $\mathrm{ft}_{\mathrm{x}}$ and $\mathrm{ft}_{\mathrm{y}}$ are 2.28 and $0.97 \mathrm{~N} / \mathrm{mm}^{2}$, respectively, the mechanical properties were considered in order to fit the latter values. The bricks dimensions are $215 \times 65 \times 102.5 \mathrm{~mm}^{3}$ and the thickness of the joints is $10 \mathrm{~mm}$.

The behaviour of the interfaces is obviously holonomic and orthotropic with softening, because it is derived from the aforementioned homogenization strategy. The procedure allow to obtain stress and strain curves for each angle of the interface and for each bending moment direction. Thus, the material orthotropy is taken in consideration by defining different input stress-strain relationships according to the trusses plane. Figure 5 presents the holonomic stress-strain curves obtained by the homogenization procedure.

\subsection{Material model for interfaces}

At a first stage, the holonomic homogenization model allows obtaining the masonry material properties accounting the strain softening regime. Furthermore, this information should serve as input for the analysis at a structural level. Thus, the novel discrete element model implemented at the finite element package ABAQUS must be able to receive this data.

A material model capable of representing the defined masonry behaviour, i.e. elastic and inelastic range both for compression and tension, has to be adopted. ABAQUS offers several material models able to reproduce damage. These models are suitable for concrete and other quasi-brittle materials. For instance, the smeared crack concrete model, the 
brittle crack concrete model and the concrete damage plasticity model. Particularly, the concrete damage plasticity model was selected. It allows to fully represent the inelastic behaviour of masonry, by defining stress-strain curves for both axial and torque trusses of the system. For further comments concerning the model and its practical application on ABAQUS, see (Wahalathantri et al. 2011).

Simplified holonomic curves were considered for each truss, see Figure 5. To avoid convergence and run time problems, a slight quasi-horizontal branch in the peak of the curves were adopted, to avoid abrupt stiffness losses. For the simulation, the post-failure stress-strain behaviour must be introduced in the material information parameters. Specifically, ABAQUS requires the introduction of the cracking strain $\tilde{\varepsilon}_{t}^{c k}$, which can be obtained for each point of the holonomic curve by equation 7 :

$\tilde{\varepsilon}_{t}^{c k}=\varepsilon_{t}-\varepsilon_{o}^{e l}$

where $\varepsilon_{o}^{e l}$ is the elastic strain corresponding to the undamaged material and $\varepsilon_{t}$ is the total strain of the holonomic curve. Damage parameters $d_{t}$ should also be introduced.

\section{MACRO-SCALE VALIDATION: COMPARISON BETWEEN NUMERICAL AND EXPERIMENTAL RESULTS}

The macro-scale validation of the holonomic homogenization model was achieved by analysing masonry panels subjected to out-of-plane loads. The aim is to conclude about the ability of the model to reproduce the nonlinear out-of-plane response of masonry. Available experimental data of windowed panels in two-way bending was used. The latter resulted from the studies of Chong et al. (Chong et al. 1994) at the University of Plymouth.

The studied walls have different geometries and are represented in Figure 6. Five panels in running bond texture using solid clay bricks were tested and designated by SB (Southcombe et al. 1995; Chong et al. 1994). The panels SB01 and SB05 are replicates, thus only four panels (SB01-SB04) are taken in account. The panels were loaded by air-bags until failure, whereas both the pressure and displacement at the middle span of the free edge were monitored. Thus, the analysis comparison will be done in terms of pressure load and displacement in each masonry panel.

The adopted mesh and observed failure mechanism for each panel at a macro-scale is represented at Figure 7. It is important to address that the mesh at the macro-scale is independent from the mesh adopted in the RVE at a meso-scale and from the masonry texture, i.e. units' geometry.

A refined mesh was adopted for the analysis; 1122 discrete elements for panel SB01/05, 892 discrete elements for panel SB02, 987 discrete elements for
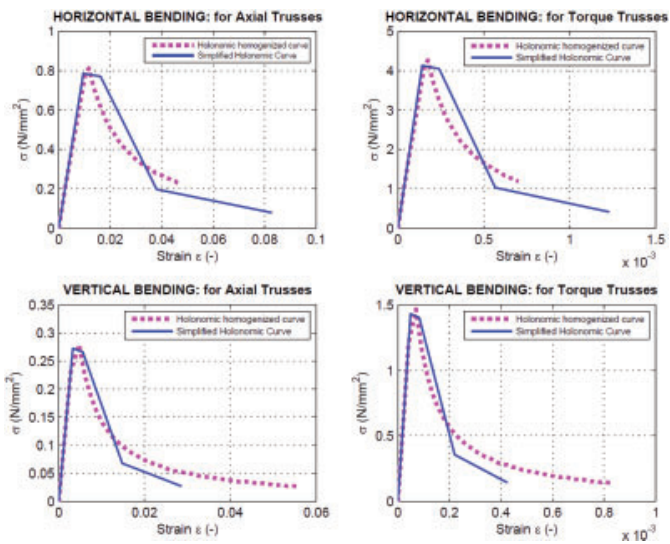

Figure 5. Holonomic homogenized curves adopted for the simulation at a structural scale.

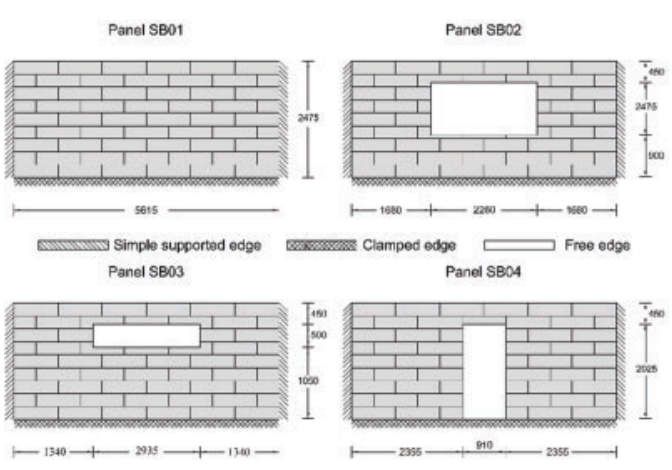

Figure 6. Masonry panels out-of-plane loaded at the University of Plymouth (Chong et al. 1994); the geometry and boundary conditions description.
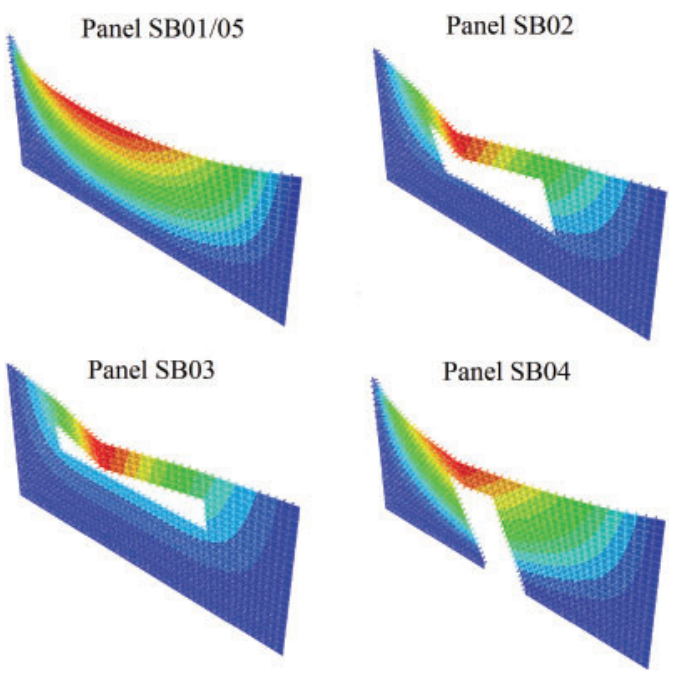

Figure 7. Observed failure mechanisms of the four studied panels. 

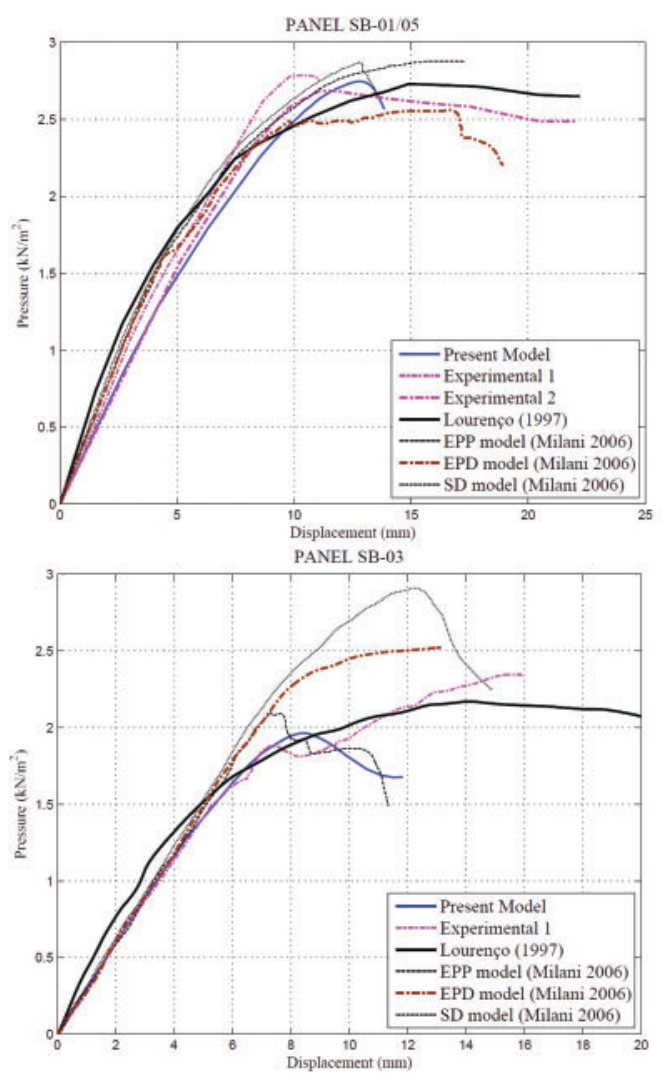
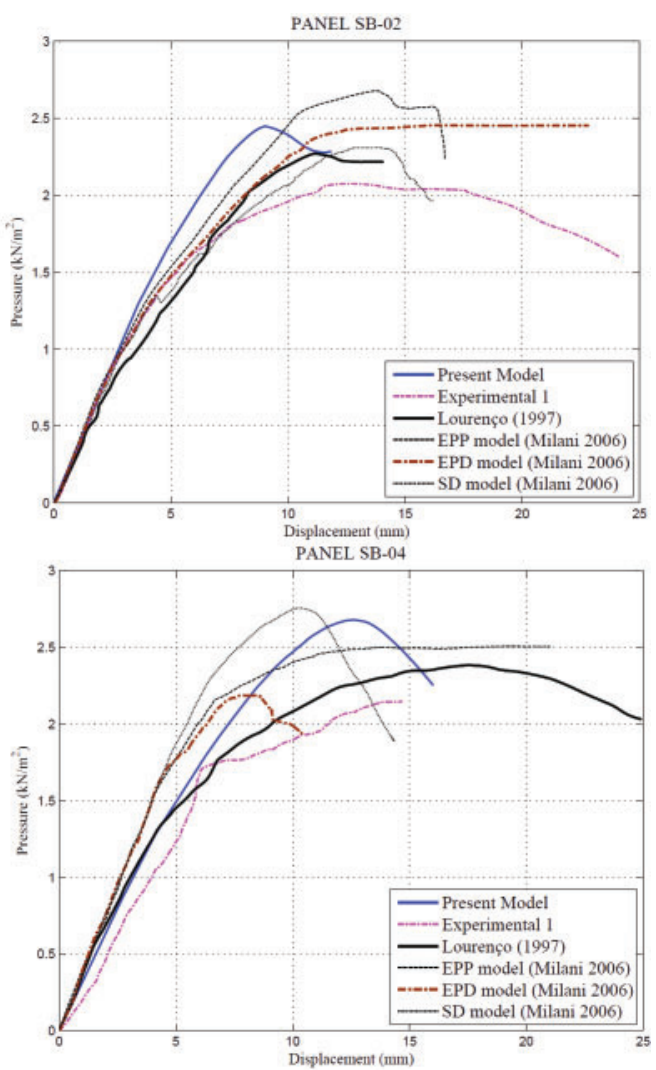

Figure 8. Numerical and experimental curves: pressure load vs displacement.

panel SB03 and 960 discrete elements for panel SB04 (each discrete element has 4 quadrilateral rigid plates). The latter discretization was assumed and no mesh dependence study was undertaken at this point. Nevertheless, each nonlinear static analysis at each panel, with the present refined mesh, took around 9 minutes. A computer with an Intel Core i7-4710MQ $2.50 \mathrm{GHz}$ processor was used to perform the simulations. This running time accounts the pre-homogenization step required before the analysis and could be minimized, if a coarser mesh is adopted. However, it is important to understand that softening is being represented and insomuch the associated convergence problems cannot be avoided.

Figure 8 shows the comparison between the numerical and experimental results (Chong et al. 1994), concerning pressure load and displacement at the middle node of the free edge. In addition to the present model being under study, results from an anisotropic macro-model by Lourenço (Lourenço 2000), an elastic perfectly-plastic homogenized model designated as EPP-model (Milani \& Tralli 2011), a simplified deteriorating model based on homogenized limit analysis designated as SD model (Milani \& Tralli 2011) and finally a simplified quadratic programming elasticplastic model by Milani, in which deterioration of interfaces (ultimate bending moment) is considered. For the sake of conciseness, the reader is referred to (Lourenço 2000) and (Milani \& Tralli 2011), in order to analyse with further detail each of the aforementioned models.

The comparison allows to conclude that the obtained results are good, both in terms of collapse load and displacements prediction (in general, less that $20 \%$ error). On one hand, it is underlined that for the panel SB01 the results are similar to the ones obtained by Lourenço (1997) (Lourenço 2000). On the other hand, it is highlighted that the results for Panel SB02 tend to overestimate the collapse load. This panel is the one with the largest opening. It is important to address that the present model is not able to directly follow diagonal yield lines. Even so, the used quadrilateral mesh is refined enough to minimize mesh dependence and the differences concerning the experimental results are not so significant.

The results shows the capacity of the model to obtain good results in panels with complex geometries, however with small dimensions. The analysis were performed without any pre-compression state. The homogenized model was prepared to compute the final stress-strain curves bearing a defined pre-compression state, but a future validation is required. 


\section{CONCLUSIONS}

A two-step procedure was presented to study the nonlinear static behaviour of masonry panels subjected to out-of-plane loading. The first step concerns the homogenization model based on a holonomic approach. This is performed at a meso-scale through a FE discretization of the unit cell, the so-called representative volume element (RVE) and allows to obtain the curvature-bending moment diagrams for each direction, i.e. masonry orthotropy. Each RVE was subdivided in 40 layers across its thickness. For each layer, a plane-stress boundary problem was solved in which the nonlinearity is concentrated only on joint interfaces, accounting for both tensile and compressive strength and strain softening.

Being a new methodology, at a structural scale, the simulation is done within a novel discrete element model implemented in the Finite Element software package ABAQUS (Abaqus 2008). The latter is composed by quadrilateral rigid plates connected by a system of rigid beams, axial and torque trusses. This system represents the holonomic behaviour of the interfaces obtained previously.

The validation of the model was performed through nonlinear static analysis on masonry panels. The case study concerns the masonry panels studied at the University of Plymouth (Chong 1993; Chong et al. 1994). The comparison between numerical and experimental results considers the applied pressure load and the displacement at a given node. A good agreement was obtained between the capacity curves.

At last, it is important to address the advantage of the procedure and its efficiency by using rigid plates, minimizing the complexity regarding plastic phenomena problems. Also, it is noteworthy that there are several advantages by being the model connected and within the FE package ABAQUS. The key points are the effectiveness and robustness of the software to solve problems accounting to the post-elastic behaviour with softening. In addition, the possibility to extend its use to other characters, as researches or professionals and the potential to extend the model to other fields, as the dynamic one.

\section{REFERENCES}

Abaqus, 2008. Dassault Systèms Simulia Corp.

Akhaveissy, A. H. \& Milani, G., 2013. A numerical model for the analysis of masonry walls in-plane loaded and strengthened with steel bars. International Journal of Mechanical Sciences, 72, pp. 13-27. Available at: http://linkinghub.elsevier.com/retrieve/pii/S00207403130 00787 [Accessed November 20, 2014].

Anthoine, A., 1995. Derivation of the in-plane elastic characteristics of masonry through homogenization theory. International Journal of Solids and Structures, 32(2), pp. 137-163. Available at: http://www.sciencedirect.com/ science/article/pii/002076839400140R [Accessed January 7,2015$]$.

Bruneau, M., 1994. Seismic evaluation of unreinforced masonry buildings - a state-of-the-art report. Canadian Journal of Civil Engineering, 21, pp. 512-539.
Casolo, S. \& Milani, G., 2013. Simplified out-of-plane modelling of three-leaf masonry walls accounting for the material texture. Construction and Building Materials, 40, pp. 330-351. Available at: http://www.sciencedirect.com/ science/article/pii/S0950061812007684 [Accessed January 29,2015$]$.

Chong, V., Southcombe, C. \& May, I., 1994. The behavior of laterally loaded masonry panels with openings. In Proceedings of 3rd international masonry conference. London, UK: Proceedings of the British Masonry Society. pp. 178-82.

Chong, V.L., 1993. The behaviour of laterally loaded masonry panels with openings. Available at: https://pearl.plymouth. ac.uk//handle/10026.1/846 [Accessed October 21, 2015].

D'Ayala, D.F. \& Paganoni, S., 2010. Assessment and analysis of damage in L'Aquila historic city centre after 6th April 2009. Bulletin of Earthquake Engineering, 9(1), pp. 81104. Available at: http://link.springer.com/10.1007/s105 18-010-9224-4 [Accessed November 25, 2015].

Dizhur, D. et al., Performance of Masonry Buildings and Churches in the 22 February 2011 Christchurch Earthquake. Bulletin of the New Zealand Society for Earthquake Engineering, 44(4). Available at: http://repositorium.sdum.uminho.pt/handle/1822/15645.

de Felice, G., 2011. Out-of-Plane Seismic Capacity of Masonry Depending on Wall Section Morphology. International Journal of Architectural Heritage, 5(4-5), pp. 466-482. Available at: http://www.tandfonline.com/doi/ abs/10.1080/15583058.2010.530339\#.VMfTkWisURo [Accessed January 7, 2015].

Geers, M.G.D., Kouznetsova, V.G. \& Brekelmans, W.A.M., 2010. Multi-scale computational homogenization: Trends and challenges. Journal of Computational and Applied Mathematics, 234(7), pp. 2175-2182. Available at: http://www.sciencedirect.com/science/article/pii/S03770 42709005536 [Accessed January 29, 2015].

Gilbert, M., Casapulla, C. \& Ahmed, H.M., 2006. Limit analysis of masonry block structures with non-associative frictional joints using linear programming. Computers \& Structures, 84(13-14), pp. 873-887. Available at: http://www.sciencedirect.com/science/article/pii/S00457 94906000356 [Accessed January 27, 2015].

Kaplan, H. et al., 2010. Structural damages of L'Aquila (Italy) earthquake. Natural Hazards and Earth System Sciences, 10, pp. 499-507.

Kawai, T., 1977. New Discrete Structural Models and Generalization of the Method of Limit Analysis. In Finite Elements in Nonlinear Mechanics, P.G. Bergan et al. eds. Tapir Publishers, pp. 885-906.

Lourenço, P.B., 2000. Anisotropic Softening Model for Masonry Plates and Shells. Journal of Structural Engineering, 126(9), pp. 1008-1016. Available at: http:// ascelibrary.org/doi/abs/10.1061/\%28ASCE\%290733-944 $5 \% 282000 \% 29126 \% 3$ A9\%281008\%29? journalCode=jse ndh [Accessed January 7, 2015].

Lourenço, P.B., 1996. Computational strategies for masonry structures. PhD Thesis. Delft University of Technology, Delft, The Netherlands.

Lourenço, P.B., 2002. Computations on historic masonry structures. Progress in Structural Engineering and Materials, 4(3), pp. 301-319. Available at: http://doi.wiley.com/ 10.1002/pse.120 [Accessed January 7, 2015].

Lourenço, P.B. et al., 2007. Failure analysis of Monastery of Jerónimos, Lisbon: How to learn from sophisticated numerical models. Engineering Failure Analysis, 14(2), pp. 280-300. Available at: http://www.sciencedirect.com/ science/article/pii/S1350630706000410 [Accessed January 27,2015$]$. 
Lourenço, P.B., 2008. Structural masonry analysis: recent developments and prospects, University of Newcastle, Australia. Available at: http://repositorium.sdum.uminho. $\mathrm{pt} /$ handle/1822/17176 [Accessed January 22, 2015].

Lourenço, P.B., De Borst, R. \& Rots, J.G., 1997. A plane stress softening plasticity model for orthotropic materials. International Journal for Numerical Methods in Engineering, 40(21), pp. 4033-4057. Available at: http://doi.wiley.com/10.1002/\%28SICI\%2910970207\%2819971115\%2940\%3A21\%3C4033\%3A\%3AAI D-NME248\%3E3.0.CO\%3B2-0 [Accessed January 27, 2015].

Luciano, R. \& Sacco, E., 1997. Homogenization technique and damage model for old masonry material. International Journal of Solids and Structures, 34(24), pp. 3191-3208. Available at: http://www.sciencedirect.com/science/article/ pii/S0020768396001679 [Accessed March 20, 2015].

Memon, B.-A. \& Su, X., 2004. Arc-length technique for nonlinear finite element analysis. Journal of Zhejiang University. Science, 5(5), pp. 618-28. Available at: http://www.ncbi.nlm.nih.gov/pubmed/15083550 [Accessed November 21, 2014].

Mendes, N. \& Lourenço, P.B., 2014. Sensitivity analysis of the seismic performance of existing masonry buildings. Engineering Structures, 80, pp. 137-146. Available at: http://www.sciencedirect.com/science/article/pii/S01410 29614005288 [Accessed January 27, 2015].

Milani, G., Lourenço, P. \& Tralli, A., 2007. 3D homogenized limit analysis of masonry buildings under horizontal loads. Engineering Structures, 29(11), pp. 3134 3148. Available at: http://www.sciencedirect.com/science/ article/pii/S0141029607001046 [Accessed November 10, 2014].

Milani, G., Lourenço, P. \& Tralli, A., 2006. Homogenization Approach for the Limit Analysis of Out-ofPlane Loaded Masonry Walls. Journal of Structural Engineering, 132(10), pp. 1650-1663. Available at: http://ascelibrary.org/doi/abs/10.1061/(ASCE)0733-9445 (2006)132:10(1650) [Accessed January 7, 2015].

Milani, G. \& Lourenço, P.B., 2010. A simplified homogenized limit analysis model for randomly assembled blocks out-of-plane loaded. Computers \& Structures, 88(11-12), pp. 690-717. Available at: http://www.sciencedirect.com/ science/article/pii/S0045794910000532 [Accessed January 19,2015$]$.

Milani, G. \& Tralli, A., 2011. Simple SQP approach for outof-plane loaded homogenized brickwork panels, accounting for softening. Computers \& Structures, 89(1-2), pp. 201-215. Available at: http://www.sciencedirect.com/ science/article/pii/S0045794910002191 [Accessed January 29,2015$]$.
Milani, G. \& Venturini, G., 2011. Automatic fragility curve evaluation of masonry churches accounting for partial collapses by means of 3D FE homogenized limit analysis. Computers \& Structures, 89(17-18), pp. 16281648. Available at: http://www.sciencedirect.com/science/ article/pii/S0045794911001271 [Accessed January 29, 2015].

Pegon, P. \& Anthoine, A., 1997. Numerical strategies for solving continuum damage problems with softening: Application to the homogenization of Masonry. Computers \& Structures, 64(1-4), pp. 623-642. Available at: http://www.sciencedirect.com/science/article/pii/S00457 94996001538 [Accessed March 20, 2015].

Peña, F. et al., 2010. Numerical models for the seismic assessment of an old masonry tower. Engineering Structures, 32(5), pp. 1466-1478. Available at: http://www.sciencedirect.com/science/article/pii/S01410 29610000283 [Accessed January 27, 2015].

Roca, P. et al., 2013. Continuum FE models for the analysis of Mallorca Cathedral. Engineering Structures, 46, pp. 653 670. Available at: http://www.sciencedirect.com/science/ article/pii/S014102961200404X [Accessed December 19, 2014].

Silva, L.C., 2013. Analysis of Christchurch Catholic Basilica, New Zealand. University of Minho. Available at: http://hdl.handle.net/1822/30809 [Accessed January 16, 2015].

Sorrentino, L. et al., 2013. The performance of churches in the 2012 Emilia earthquakes. Bulletin of Earthquake Engineering, 12(5), pp. 2299-2331. Available at: http://link.springer.com/10.1007/s10518-013-9519-3 [Accessed January 7, 2015].

Southcombe, C., May, I. \& Ching, V., 1995. The behavior of brickwork panels with openings under lateral load. In Proceedings of the 4th international masonry conference, vol. 1. London, UK: Proceedings of the British Masonry Society. pp. 105-10.

Spence, R. \& Coburn, A., 1992. Strengthening building of stone masonry to resist earthquakes. Meccanica, 27, pp. 213-221.

Wahalathantri, B.L. et al., 2011. A material model for flexural crack simulation in reinforced concrete elements using ABAQUS. Proceedings of the First International Conference on Engineering, Designing and Developing the Built Environment for Sustainable Wellbeing. Available at: http://eprints.qut.edu.au/41712/1/eddBE2011_260-264_ Wahalathantri.pdf [Accessed December 9, 2015]. 